\title{
Multi-phases problematic in the oil \& gas industry: solid phases combined to fluid phases
}

\author{
P. Duchet-Suchaux
}

Total SA, 2, place Jean MIllier La Défense 6, 92400 COURBEVOIE, France

By definition the oil \& gas industry is used to handling fluid phases, vapor and liquid, as the wells produce always water gas and oil in very different proportions. But in addition under certain circumstances solid phases could appear in different locations (reservoir, pipe-lines or in the process facilities), for instance we could have appearance and deposit of ice, gas hydrates, wax, mercury, sulfur or solid $\mathrm{CO}_{2}$. Most of the time the operating conditions of the fields will be chosen in order to avoid any solid particle in the fluids that could have dramatic consequences on the installations but it is not always possible. In anyway the presence of solid phases should be detected by the simulators used for designing the future installations or assisting the engineers in charge of the production. It means that there is a crucial need of predictive, reliable and robust thermodynamic models that can perform calculations of complex equilibrium with 3 fluid phases combined with several solid phase and provide their properties (density, thermal conductivity, heat capacity,...), for instance gas-oilwater-gas hydrates-wax.

We will present the situations where solid phases can appear in the oil \& gas installations their impacts, the current available thermodynamic models and our expectations for the future. 